\title{
Determining the Moisture Content of Pre-Wetted Lightweight Aggregate: Assessing the Variability of the Paper Towel and Centrifuge Methods
}

\author{
A. Miller, R. Spragg, F. C. Antico, W. Ashraf, T. Barrett, A. Behnood, Y. Bu, Y. Chiu, B. Desta, Y. Farnam, \\ H. Jeong, W. Jones, C. Lucero, D. Luo, C. Nickel, P. Panchmatia, K. Pin, S. Qiang, C. Qiao, \\ H. Shagerdi, R. Tokpatayeva, C. Villani, A. Wiese, S. Woodard, and W. J. Weiss \\ Lyles School of Civil Engineering, Purdue University \\ School of Civil Engineering, Xi'an University of Architecture and Technology \\ F. Macobatti \\ University of Brescia - DICATEM \\ Q. Tian \\ Jiangsu Research Institute of Building Science
}

\begin{abstract}
Internally cured (IC) concrete is frequently produced in North America using pre-wetted lightweight aggregate (LWA). One important aspect associated with the production of quality IC concrete is the accurate determination of the moisture content, including absorbed moisture and surface moisture of the LWA. Knowledge of the moisture content enables aggregate moisture corrections to be made for the concrete mixture, thereby enabling an accurate water-to-cement ratio to be maintained. Two methods for determining the moisture content of LWA include the specified ASTM C1761-13b "paper towel method" and a method that uses a centrifuge (Miller, Barrett, Zander, \& Weiss, 2014). There are limited data available on the variability associated with either of these approaches when the test is performed by multiple users. In this study, the absorption of four commercially available LWAs was tested by a single operator in a single laboratory using the centrifuge method. In addition, the absorption of three commercially available LWAs was tested by 25 users performing both experimental methods. This article provides an estimation of precision associated with both a single operator and multiple operators performing both the paper towel method and the centrifuge method to find the absorption of pre-wetted lightweight fine aggregate.
\end{abstract}

\section{INTRODUCTION}

Pre-wetted fine lightweight aggregate (LWA) is often used in the production of internally cured (IC) concrete. The water that was absorbed in the LWA is released and replaces the volume of space that would be created by chemical shrinkage during the hydration reaction. To reach the required amount of water absorption, the fine LWA is typically stored in stockpiles and pre-wetted with hoses or sprinklers for a specified period of time. This practice typically yields a pre-wetted LWA that is sufficient for internal curing, but the pre-wetting may be problematic for consistent production as surface moisture can vary greatly. One important aspect associated with quality control of IC concrete is being able to determine the moisture content, including absorbed moisture and surface moisture associated with the pre-wetted LWA.

Water absorbed by the pre-wetted LWA is not available for initial hydration of the binder and is not considered in the water-to-cement ratio (w/c). Surface moisture, however, is free water within the mixture and must be taken into account when determining the $\mathrm{w} / \mathrm{c}$. If surface moisture is underestimated, the aggregate will contain additional free water and the $\mathrm{w} / \mathrm{c}$ will be higher than the designed value. This may result in decreased strength and increased permeability (Castro, 2011; Popovics, 1990). Likewise, if surface moisture is overestimated, the aggregate will contain less free water and the mixture will have a lower w/c than designed. The lower w/c could lead to decreased workability and problems with consolidation if it is not overcome with admixtures (Kennedy, 1940). While both surface moisture and absorbed moisture are important parameters for consideration in IC concrete mixture designs, this study focuses primarily on LWA absorption.

The absorption of LWA is one value used to determine the amount of LWA that should be used to replace natural fine aggregate with LWA in the mixture design for IC concrete (Bentz, Lura, \& Roberts, 2005). LWA typically has an absorption much higher than most conventional aggregates, ranging from 6 to $30 \%$ in North American commercially produced LWAs (Castro, Keiser, Golias, \& Weiss, 2011). Absorption of a given LWA is primarily dependent on the duration of 
pre-wetting, but may be influenced by environmental conditions as well (i.e., temperature, humidity, wind, precipitation, and moisture gradients within a stockpile), which may cause sections of the stockpile to dry while others may not. Because of these factors, absorption and surface moisture of LWA can vary greatly from day to day. This increases the potential for errors to be made when adjusting the batch water for free moisture in the system during production.

While it is possible to adjust the concrete mixture design for the measured absorption on the day of production, it is frequently more practical to hold the volume of LWA constant in the concrete mixture design and allow for the absorption measured the day of the cast to exceed the design value. This method assures that the system still contains enough internal curing water as per the Bentz equation while also protecting the same paste volume (Bentz \& Snyder, 1999).

For IC concrete design and field batching, it is important that: (1) $24 \mathrm{~h}$ aggregate absorption can be accurately determined for the mixture design, and (2) measured absorption of aggregate can be determined prior to batching concrete to assure design absorption has been reached or exceeded. Adjustments can then be made to the mixture design if design absorption is not reached, and it may be necessary to adjust for specific gravity changes if the aggregate has absorbed more or less than the design value so that the proper amount of LWA can be batched and the concrete mixture designs yield as designed. Accurately determining the absorption of LWA is an essential part of implementing IC concrete.

There are several methods that could be used to determine the absorption of LWA. ASTM C1761-13b specifies the use of a method often referred to as the "paper towel method." In this method, pre-wetted fine LWA is dried manually by patting a sample with paper towels until moisture no longer appears on the paper towels. At this time, the aggregate is deemed to be in the pre-wetted, surface-dry condition (ASTM International, 2013). While this method is effective for coarse aggregate, it can be problematic for fine aggregate. It is common for fine material to be trapped in the paper towels and lost during drying. The standard only specifies the use of paper towels that are "commercial grade, either folded type or roll type." This may lead to inconsistencies in measurements due to the varying absorptive capacities of commercial grade paper towels. Some paper towels will inherently absorb fluid from smaller surface pores than others. Another, and potentially larger, source of error may be introduced by the operator of the test. The standard does not specify how hard to press the surface of the aggregate against the paper towel. It is possible to lightly pat the surface of the aggregate with the paper towel and observe no visible moisture on the towel, but if pressure is applied to the paper towel on the aggregate, it may pull moisture from the surface pores. The demarcation of the pre-wetted surfacedry condition of the aggregate is largely subjective in ASTM C1761-13b, which can lead to discrepancies between multiple people performing the same test on the same aggregate stockpile.

The "centrifuge method" is an alternative test, which has recently been evaluated for internal curing applications (Miller et al., 2014). In this method, a sample of a pre-wetted LWA stockpile is placed in a centrifuge. Surface moisture (free moisture) is then extracted from the aggregate as the centrifuge rotates at $2000 \mathrm{rpm}$ for $3 \mathrm{~min}$. At the conclusion of this 3-min period, the aggregate is considered to be in the pre-wetted surface-dry condition. Whereas the paper towel method depends on absorptive capacity of paper towel used and pressure applied to the paper towel when patting dry, the mechanism of the centrifuge is constant and based on the speed at which it rotates. The centrifuge method will consistently remove water from the surface and from surface pores of the same radius.

There is limited availability of precision and bias for either test. There are no bias statements because no accepted reference values for LWA exist. ASTM C1761$13 \mathrm{~b}$ has a statement on pooled single operator single laboratory standard deviation of $0.3 \%$ for absorption. This was determined by testing LWA from four sources after submersion in water for $72 \mathrm{~h}$. The value of $72 \mathrm{~h}$ absorption ranged from 9 to $28 \%$ for the four aggregates (ASTM International, 2013). The goal of this paper was to provide a similar precision statement to the one listed in ASTM C1761-13b and to provide a statement for multi-user single laboratory precision for both the paper towel method and the centrifuge method.

\section{EXPERIMENTAL PROGRAM}

The experimentation was broken into two parts. In the first part, the centrifuge method was used by a single user on LWA from four different sources. Aggregate would be pre-wetted by submersion in water at room temperature for $24 \mathrm{~h}$ prior to testing. At $24 \mathrm{~h}$, the water is decanted from the aggregate, taking care to avoid loss of fines. The aggregate was stirred to reduce segregation that may have occurred while soaking and decanting. A total of $600 \mathrm{~g}$ of the aggregate was then placed in a centrifuge bowl of known mass. The centrifuge bowl was then placed in the centrifuge unit, covered with $4 \mu \mathrm{m}$ filter and lid, and tightened into place. The centrifuge was then powered on and the test was run for 3 min at a speed of $2000 \mathrm{rpm}$. The mass of the bowl and pre-wetted surface-dry aggregate was then recorded. The aggregate was then oven-dried to constant mass $( \pm 0.1 \mathrm{~g})$ at $105^{\circ} \mathrm{C}$, 
and the mass of oven-dry aggregate was recorded. Absorption was then calculated using Equation (1).

$$
\text { Absorption }=\frac{M_{\mathrm{PSD}}-M_{\mathrm{OD}}}{M_{\mathrm{OD}}}
$$

In Equation (1), $M_{P S D}$ refers to the mass of the prewetted surface-dry aggregate and $M_{\mathrm{OD}}$ refers to the mass of the oven-dry aggregate. The pooled single operator standard deviation of absorption for one laboratory could then be determined and compared to that of the paper towel method.

In the second part of this study, multiple operator single laboratory precision data were to be obtained from 25 users. For this portion, the test method procedure was not explained or taught to the operators. Each operator was provided with a copy of ASTM C1761$13 \mathrm{~b}$ and a copy of the procedure for the centrifuge method as described by Miller et al. Each operator was provided with access to all materials and tools listed in the specifications. For safety, each operator was trained on the centrifuge, but no instruction on the method was given. LWA from three different sources was used. Each operator was presented with a pan of unidentified LWA that had been pre-wetted for $24 \mathrm{~h}$. The operator first performed the specified ASTM C1761-13b test for absorption. Water was decanted from the pan containing the LWA sample. A representative sample of $500-750 \mathrm{~g}$ was transferred to a non-absorbent surface covered in paper towels. Aggregate was exposed to a gently moving current of air and then surface of the aggregate was patted with paper towels. The aggregate was stirred frequently and the bottom paper towels were to be replaced whenever they became too saturated to absorb moisture. This process was repeated until a clean paper towel no longer showed any sign of moisture after patting the LWA. This mass was recorded as the pre-wetted surface-dry mass. The aggregate was then oven-dried, and the mass of the oven-dry aggregate was recorded. Absorption was calculated using Equation (1).

After performing the paper towel method, the operator then used the centrifuge method to determine the absorption of a separate sample of the same unidentified aggregate. The procedure for the centrifuge method was the same as previously described. The absorption of the LWA was again calculated using the previously described equation.

In addition to obtaining the absorption from the paper towel method and the centrifuge method, test durations were also recorded by each user. For both tests, the beginning of the test was considered to be when the decanted aggregate was separated from the sample for the test. The end of the test was considered to be when the aggregate was placed in the oven for oven drying.

\section{RESULTS AND DISCUSSION}

The first experiment sought to establish a comparison of the single operator single laboratory precision of the centrifuge method to the precision listed in ASTM C1761-13b for absorption. Four LWAs from different sources were submerged in water for $24 \mathrm{~h}$ and tested using the aforementioned procedure. Each aggregate was tested six times. The results of this testing can be seen in Table 1.

Table 1. Results of single operator single laboratory absorption testing using the centrifuge method.

\begin{tabular}{lccc}
\hline LWA source & $\begin{array}{c}\text { Average } \\
\text { absorption (\%) }\end{array}$ & $\begin{array}{c}\text { Standard } \\
\text { deviation (\%) }\end{array}$ & $\begin{array}{c}\text { Coefficient } \\
\text { of variation }\end{array}$ \\
\hline $\begin{array}{l}\text { Buildex } \\
\text { Marquette }\end{array}$ & 20.13 & 0.43 & 0.021 \\
Stalite & 8.98 & 0.06 & 0.007 \\
$\begin{array}{l}\text { Trinity* } \\
\text { Boulder }\end{array}$ & 18.84 & 0.18 & 0.010 \\
$\begin{array}{l}\text { Utelite } \\
\text { Pooled standard deviation (\%) }\end{array}$ & 0.25 & - \\
Average coefficient of variation & - & 0.010 \\
\hline *Formerly TXI & & &
\end{tabular}

ASTM C1761-13b provides a precision statement for using the paper towel method to test absorption for a single user and single laboratory. The paper towel method has a pooled single operator standard deviation of $0.3 \%$ (ASTM International, 2013). The results in Table 1 show that the pooled single operator standard deviation for the centrifuge method is $0.25 \%$.

The second experiment examined precision of both the paper towel method and the centrifuge method for absorption when multiple users perform the test. Three LWAs from different sources were submerged in water for $24 \mathrm{~h}$ and tested using the methods outlined in the experimental program section of this paper. Twenty-five operators followed the procedures to the best of their abilities without receiving training on the methods. Absorption results and test duration were then reported for each test, as seen in Table 2.

Neither method has an established precision for multiple users. Following the ASTM C1761-13b standard for the paper towel test, pooled standard deviations were calculated as a measure of precision. The paper towel method saw a multiple user pooled standard deviation of $4.5 \%$, while the centrifuge method had a multiple user pooled standard deviation of $0.45 \%$. This finding is significant, as it shows that the centrifuge method could improve precision between users by an order of magnitude. The average coefficient of variation was also calculated for the three aggregates. Again, the centrifuge was ten times as precise, as the average 
Table 2. Results from multiple operator single laboratory variability testing for absorption using both the paper towel test (top) and the centrifuge method (bottom).

\begin{tabular}{lccc}
\hline LWA source & $\begin{array}{c}\text { Average } \\
\text { absorption } \\
(\%)\end{array}$ & $\begin{array}{c}\text { Standard } \\
\text { deviation } \\
(\%)\end{array}$ & $\begin{array}{c}\text { Coefficient } \\
\text { of variation }\end{array}$ \\
\hline $\begin{array}{l}\text { Paper towel method } \\
\text { Buildex Marquette }\end{array}$ & 21.26 & 2.26 & 0.106 \\
Stalite & 10.51 & 4.91 & 0.467 \\
Utelite & 21.75 & 5.34 & 0.246 \\
Pooled standard deviation (\%) & 4.51 & - \\
Average coefficient of variation & - & 0.273 \\
Centrifuge method & & & \\
Buildex Marquette & 20.18 & 0.56 & 0.028 \\
Stalite & 8.47 & 0.27 & 0.032 \\
Utelite & 18.96 & 0.47 & 0.025 \\
Pooled standard deviation (\%) & 0.45 & - \\
\multicolumn{2}{l}{ Average coefficient of variation } & - & 0.028 \\
\hline
\end{tabular}

coefficient of variation was 0.273 for the paper towel test and 0.028 for the centrifuge method. This shows the average test duration for both the paper towel method and the centrifuge method.

Table 3. Observed testing durations for 25 operators performing the paper towel and centrifuge method.

\begin{tabular}{lcc}
\hline Testing method & $\begin{array}{c}\text { Average duration } \\
(\min )\end{array}$ & $\begin{array}{c}\text { Standard } \\
\text { deviation }(\min )\end{array}$ \\
\hline Paper towel & 42 & 13.2 \\
Centrifuge & 12 & 5.0 \\
\hline
\end{tabular}

Among 25 users, the paper towel method took an average of $42 \mathrm{~min}$, while the centrifuge method took $12 \mathrm{~min}$. This time savings seen by using the centrifuge method is substantial, especially when considering quality control operations while batching IC concrete. A faster, more accurate test like the centrifuge method would allow for absorption verification and moisture corrections to be easily made at the start of each day and throughout the day.

\section{CONCLUSION}

This article evaluated the use of two methods that are used to determine the absorption of pre-wetted lightweight fine aggregate. Precision data were previously only available for single operator, single laboratory testing using the paper towel method (ASTM C1761-13b) and no data were available for the centrifuge method. The first experiment provided single operator, single laboratory absorption precision data for the centrifuge method so that the two methods could be compared. The results showed that centrifuge method had a slightly better single operator, single laboratory precision $(0.25 \%)$ than the paper towel method $(0.3 \%)$. The second experiment built upon the first, providing multiple operator, single laboratory precision statements for both the paper towel method and the centrifuge method. Twenty-five operators performed both tests. Results from absorption measurements showed the centrifuge method to be approximately 10 times more precise than the paper towel method. In addition, test durations were recorded for both methods. The paper towel method took an average of $42 \mathrm{~min}$ to perform, while the centrifuge method averaged $12 \mathrm{~min}$ to perform.

The centrifuge method is a potential improvement on the currently specified paper towel method. The experiments performed show that the centrifuge method is slightly more precise for a single user, and is 10 times more precise when multiple operators test absorption on the same pre-wetted LWA. This increase in precision will allow for mixture design and moisture corrections to be made with accuracy, repeatability, and confidence. In addition, the centrifuge method is a considerably more rapid test for determining the moisture properties of pre-wetted LWA. Decreasing the time to perform the test will allow for rapid moisture corrections to be made to IC concrete mixture designs. This article has shown that the centrifuge method may potentially increase the speed and precision of LWA characterization and IC concrete quality control operations.

\section{ACKNOWLEDGMENTS}

This study was made possible with the help of student volunteers from a class offered in the School of Civil Engineering at Purdue University (CE 597 - Recent Advancements in Internal Curing). The experiments discussed in this article were performed in the Pankow Materials Laboratories. The authors acknowledge the support that has made these laboratories and their operation possible.

\section{REFERENCES}

ASTM C1761-13b, 2013, "Standard Specification for Lightwieght Aggregate for Internal Curing of Concrete," Annual Book of ASTM Standards, 4(2), ASTM International, West Conshohocken, PA.

Bentz, D. P., Lura, P., \& Roberts, J. W. (2005). Mixture proportioning for internal curing. Concrete International, 27(2), 35-40.

Bentz, D., \& Snyder, K. (1999). Protected paste volume in concrete: Extension to internal curing using saturated lightweight fine aggregate. Cement and concrete research, 29(11), 1863-1867. 
Castro, J. (2011). Moisture transport in cement based materials: Application to transport tests and internal curing. West Lafayette, IN: ProQuest.

Castro, J., Keiser, L., Golias, M., \& Weiss, J. (2011). Absorption and desorption properties of fine lightweight aggregate for application to internally cured concrete mixtures. Cement and Concrete Composites, 33(10), 1001-1008.

Kennedy, C. T. (1940). The design of concrete mixes. Journal of the American Concrete Institute, 36(2), 373-400.
Miller, A. E., Barrett, T. J., Zander, A. R., \& Weiss, W. J. (2014). Using a Centrifuge to determine Moisture Properties of Lightweight Fine Aggregate for Use in Internal Curing. ASTM Advances in Civil Engineering Materials, 3(1).

Popovics, S. (1990). Analysis of concrete strength versus water-cement ratio relationship. $\mathrm{ACl}$ Materials journal, 87(5), 517-529. 